\title{
Renoprotective immunosuppression by pioglitazone with low-dose cyclosporine in rat heart transplantation
}

\author{
Yosuke Tanaka, MD, Tomomi Hasegawa, MD, PhD, Zhi Chen, MD, Yutaka Okita, MD, PhD, and \\ Kenji Okada, MD, PhD
}

\begin{abstract}
Objective: The peroxisome proliferator-activated receptor $\gamma$ activator pioglitazone has recently been reported to possess pleiotropic cardioprotective and renoprotective actions. We hypothesized that pioglitazone would reduce a dose of the immunosuppressant cyclosporine after heart transplantation, resulting in beneficial protective effects for both cardiac allografts and recipient kidneys.
\end{abstract}

\begin{abstract}
Methods: Experiments were performed by using an allomismatched rat heterotopic heart transplantation model. Recipients were treated with cyclosporine with or without pioglitazone and were divided into one of 4 groups: group I, no treatment; group II, low-dose cyclosporine $\left(2 \mathrm{mg} \cdot \mathrm{kg}^{-1} \cdot \mathrm{d}^{-1}\right)$; group III, high-dose cyclosporine $\left(5 \mathrm{mg} \cdot \mathrm{kg}^{-1} \cdot \mathrm{d}^{-1}\right)$; and group IV, low-dose cyclosporine with pioglitazone $\left(3 \mathrm{mg} \cdot \mathrm{kg}^{-1} \cdot \mathrm{d}^{-1}\right)$.

Results: Cyclosporine-treated rats showed significantly longer graft survival and less graft rejection but severe renal damage in a dose-dependent manner. Compared with group II, treatment with pioglitazone with lowdose cyclosporine (group IV) significantly suppressed graft infiltration of CD4/CD8 T lymphocytes and serum concentrations of interleukin 2 and interferon $\gamma$, leading to extended graft survival up to 60 days. These immunosuppressive effects in group IV were equivalent to those in group III. In addition, recipient kidneys in group IV had few apoptotic cells, possibly through upregulation of peroxisome proliferator-activated receptor $\gamma$ and downregulation of transforming growth factor $\beta 1$, and maintained stable renal functions, as evidenced by a normalization of blood urea nitrogen, creatinine, and creatinine clearance values. In vitro experiments also confirmed the renoprotective effects of pioglitazone on cyclosporine-induced toxicity.
\end{abstract}

Conclusions: Collectively, pioglitazone can reduce a dose of cyclosporine with sufficient immunosuppressive effects. Pioglitazone treatment with low-dose cyclosporine has synergistic protective effects for cardiac allografts and recipient kidneys, leading to improvement of graft survival with a minimal cyclosporine-induced nephrotoxicity.

Recent advances in immunosuppressive agents have greatly overcome acute graft rejection and improved both graft and patient survival rates in heart transplantation. ${ }^{1,2}$ Calcineurin inhibitors, such as cyclosporine (CsA), are first-line immunosuppressants widely used after transplantation and play an important role for posttransplantation management. However, the immense therapeutic potential of CsA is severely hampered by CsA-induced nephrotoxicity. ${ }^{3,4}$ The toxic effect of CsA is dose dependent, and therefore it is generally agreed that close clinical monitoring of CsA levels is imperative to optimize safety and efficacy in limiting the degree of renal damage. ${ }^{5}$ In clinical settings immunosuppressive regimens based on the association of low-dose CsA with other drugs, such as mycophenolate mofetil, steroids, sirolimus, or everolimus, have been recommended. ${ }^{6-8}$

\footnotetext{
From the Department of Surgery, Division of Cardiovascular Surgery, Kobe University Graduate School of Medicine, Kobe, Japan.

Supported by a Japan Heart Foundation research grant.

Received for publication Jan 11, 2009; revised March 18, 2009; accepted for publication April 22, 2009; available ahead of print July 6, 2009.

Address for reprints: Kenji Okada, MD, PhD, Department of Surgery, Division of Cardiovascular Surgery, Kobe University Graduate School of Medicine, 7-5-2, Kusunoki-cho, Chuo-ku, Kobe 650-0017, Japan (E-mail: yutamo@aol.com).

J Thorac Cardiovasc Surg 2009; 138:744-51

$0022-5223 / \$ 36.00$

Copyright (c) 2009 by The American Association for Thoracic Surgery doi:10.1016/j.jtcvs.2009.04.019
}

Thiazolidinediones, which include the presently available drug pioglitazone, are well-established insulin-sensitizing agents that act as agonists of the ligand-activated transcriptional factor peroxisome proliferator-activated receptor (PPAR) $\gamma$. It has recently been reported that pioglitazone possesses pleiotropic cardioprotective $\mathrm{e}^{9-11}$ and renoprotective ${ }^{12-14}$ actions in experimental settings, including antiinflammatory and antiproliferative properties. In the field of heart transplantation, survival of cardiac allografts has been prolonged by pioglitazone administration in experimental mouse models ${ }^{15}$; however, the mechanisms and renoprotective effects have not been fully elucidated. Although pioglitazone has protective effects to limit renal damage caused by CsA in nonsurgical models, ${ }^{16}$ there are no reports of pioglitazone in reference to the dose reduction of CsA in heart transplantation.

Taken together, the aim of this study was to evaluate whether pioglitazone has a potential to reduce the dose of CsA for renal protection with immunosuppressive effects in heart transplantation.

\section{MATERIALS AND METHODS Animals \\ Forty-eight inbred male rats 16 weeks of age and weighing 280 to $300 \mathrm{~g}$ were used in the present study. Lewis (RT1) and Brown Norway (RTn) rats}




$$
\begin{aligned}
& \text { Abbreviations and Acronyms } \\
& \text { BUN }=\text { blood urea nitrogen } \\
& \text { CsA }=\text { cyclosporine } \\
& \text { IFN }=\text { interferon } \\
& \text { IL }=\text { interleukin } \\
& \text { PPAR }=\text { peroxisome proliferator-activated } \\
& \text { receptor } \\
& \text { TGF }= \\
& \text { TUNEL }=\text { transforming growth factor } \\
& \text { nick end labeling }
\end{aligned}
$$

were obtained from Charles River Japan (Yokohama, Japan). The handling of laboratory animals and their use in experiments conformed to the "Guidelines for animal experimentation" at Kobe University Graduate School of Medicine (Permission number: P080306) and the "Guide for the care and use of laboratory animals" published by the US National Institutes of Health (publication no. 85-23, revised 1996).

\section{Drugs}

Pioglitazone was provided by Takeda Chemical Industries (Tokyo, Japan). CsA (Sandimmune) was purchase from Novartis Pharmaceuticals (Tokyo, Japan). Pioglitazone diluted in normal saline was administered to recipient mice by means of gastric gavage, and CsA was administered subcutaneously.

\section{Rat Heart Transplantation Model}

Major allomismatched rat heterotopic heart transplantation was performed as described by Ono and Lindsey. ${ }^{17}$ Brown Norway rats were used as donors, and Lewis rats were used as recipients. The aorta and pulmonary artery of the donor heart were anastomosed to the recipient's abdominal aorta and inferior vena cava, respectively. During the observation period, graft rejection or survival was gauged by means of daily manual palpitation. Body weight of the recipient rats was measured once a week.

\section{Experimental Groups}

Rats were randomly divided into one of 4 groups as follows: group I received no treatment as a control, group II received low-dose CsA ( $2 \mathrm{mg}$ $\left.\cdot \mathrm{kg}^{-1} \cdot \mathrm{d}^{-1}\right)$, group III received high-dose CsA $\left(5 \mathrm{mg} \cdot \mathrm{kg}^{-1} \cdot \mathrm{d}^{-1}\right)$, and group IV received low-dose CsA $\left(2 \mathrm{mg} \cdot \mathrm{kg}^{-1} \cdot \mathrm{d}^{-1}\right)$ with pioglitazone $(3$ $\left.\mathrm{mg} \cdot \mathrm{kg}^{-1} \cdot \mathrm{d}^{-1}\right)$. In the present study 2 experiments were performed: a 1 -week end point experiment ( $\mathrm{n}=6$ in each group) and a survival experiment ( $\mathrm{n}=6$ in each group). Drugs were administered once a day beginning 3 days before heart transplantation and lasting until the 1-week end point of the experiment or a beating cessation of cardiac allografts.

\section{Specimen Preparation}

Graft hearts and recipient kidneys were harvested and rinsed in saline and fixed in $10 \%$ formalin. The formalin-fixed grafts were dehydrated in a graded ethanol bath, cleaned in xylene, embedded in paraffin, and sectioned (thickness, $4 \mu \mathrm{m}$ ) for histologic analysis.

\section{Histology}

Graft sections were stained with hematoxylin and eosin. The severity of graft rejection was graded by using a modified form of the Working Formulation of the International Society for Heart and Lung Transplantation criteria $^{18,19}: 0$, no rejection; 1 , interstitial infiltration, perivascular infiltration, or both of mononuclear cells without myocyte damage; 2 , one focal infiltration of mononuclear cells with associated myocyte damage; 3 , multifocal or diffuse infiltration of mononuclear cells with myocyte damage; and 4, multifocal or diffuse infiltration of mononuclear and polymorphous cells with extensive myocyte damage. Histopathologic evaluation was performed by an experienced observer (T.H.) who was blinded to the treatment protocol.

\section{Immunohistochemical Staining}

Immunohistochemical staining was performed with mouse anti-rat monoclonal antibodies against CD4 and CD8 (BD PharMingen, San Diego, Calif) with biotin-labeled anti-mouse immunoglobulin (Vector Laboratories, Burlingame, Calif). The Vectastain ABC kit (Vector Laboratories) was used to detect positive cells according to the manufacturer's instructions. Diaminobenzidine substrate (DakoCytomation, Carpinteria, Calif) was used as a chromogen, and cell nuclei were counterstained with hematoxylin. Positive cell numbers were quantified by counting immunoreactive cells in 10 nonoverlapping highpower fields by using the National Institutes of Health image program (version 1.63; National Institutes of Health, Bethesda, Md).

\section{Transferase-Mediated dUTP-Biotin Nick End Labeling Staining}

Terminal deoxynucleotidyl transferase-mediated dUTP-biotin nick end labeling (TUNEL) staining was performed with the In Situ Cell Death Detection Kit (Roche Applied Science, Indianapolis, Ind) to detect apoptosis in situ. Methods for the counterstaining of cell nuclei and the quantification of TUNEL-positive cells were the same as those for immunohistochemical staining.

\section{Immunofluorescent Staining}

Immunofluorescent staining was performed with primary antibodies: mouse monoclonal anti-PPAR- $\gamma$ antibody, rabbit polyclonal anti-transforming growth factor (TGF) $\beta 1$ antibody, and anti-Bax antibodies (Santa Cruz Biotechnology, Santa Cruz, Calif). Fluorescein-linked sheep antimouse antibody and donkey anti-rabbit antibody were used as secondary antibodies (Amersham Biosciences, Buckinghamshire, United Kingdom). The cell nuclei were counterstained with 4',6-diamidino-2-phenylindole (Chemicon International, Temecula, Calif).

\section{Renal Function}

Blood urea nitrogen (BUN) and creatinine levels in plasma and urine were measured with commercial assay kits (BUN-test-Wako and Creatinine-test-Wako, respectively; Wako Pure Chemicals, Osaka, Japan), according to the manufacturer's instructions. The glomerular filtration rate was calculated as creatinine clearance by using the standard formula UV/ $\mathrm{P}$, where $\mathrm{U}$ is urinary creatinine (in milligrams per deciliter), $\mathrm{V}$ is urine volume (in milliliters per minute), and $\mathrm{P}$ is plasma creatinine (in milligrams per deciliter). At 1 week after transplantation, 24-hour urine was collected from each rat housed in a metabolic cage.

\section{Quantification of Interleukin 2, Interferon $\gamma$, and TGF- $\beta 1$}

Concentrations of interleukin (IL) 2 , interferon (IFN) $\gamma$, and TGF- $\beta 1$ were measured by means of enzyme-linked immunosorbent assay with Quantikine Rat immunoassay kits (R\&D Systems, Minneapolis, Minn), according to the manufacturer's instructions.

\section{Statistics}

Database management and statistical analysis were performed with Statview version 5.0 software (SAS institute, Inc, Cary, NC). All values are expressed as means \pm standard errors of the mean for the number of mice or independent analyses. Kaplan-Meier analysis was performed to evaluate 
graft survival, and survival differences were compared by using a log-rank test. Comparisons among groups were performed with the nonparametric Mann-Whitney $U$ test.

\section{RESULTS \\ Pioglitazone Reduced CsA Dose With an Improvement of Allograft Survival}

We first confirmed an effect of CsA on the allograft survival in our rat heart transplantation model. CsA significantly prolonged the survival period in a dose-dependent manner (group I vs group II, $P=.0014$; group II vs group III, $P=.0007)$. There were no dropouts of recipient mice before the beating cessation of cardiac allograft in each group. Next we investigated the effect of pioglitazone treatment with low-dose CsA (group IV) on the allograft survival. Compared with group II, the graft survival in group IV was dramatically extended up to 60 days $(P=.0018)$. The survival period in group IV was equivalent to that in group III (Figure 1). During the survival observation in group IV, we did not find any pioglitazone-related side effects, such as fluid retention, congestive heart failure, fractures, and hepatocellular injury. There were no significant differences in body weight change among each group after transplantation.

\section{Suppression of Acute Allograft Rejection}

At 1 week after transplantation, diffuse infiltration of mononuclear or polymorphous cells with associated cardiomyocyte damage was present in most areas of cardiac allografts in group I. CsA significantly decreased the rejection scores and the numbers of infiltrating $\mathrm{CD}^{+}$and $\mathrm{CD} 8^{+}$cells in a dose-dependent manner. By means of pioglitazone treatment with low-dose CsA, far less cellular infiltration and a lack of cardiomyocyte damage was present in group IV compared with that seen in group II. There

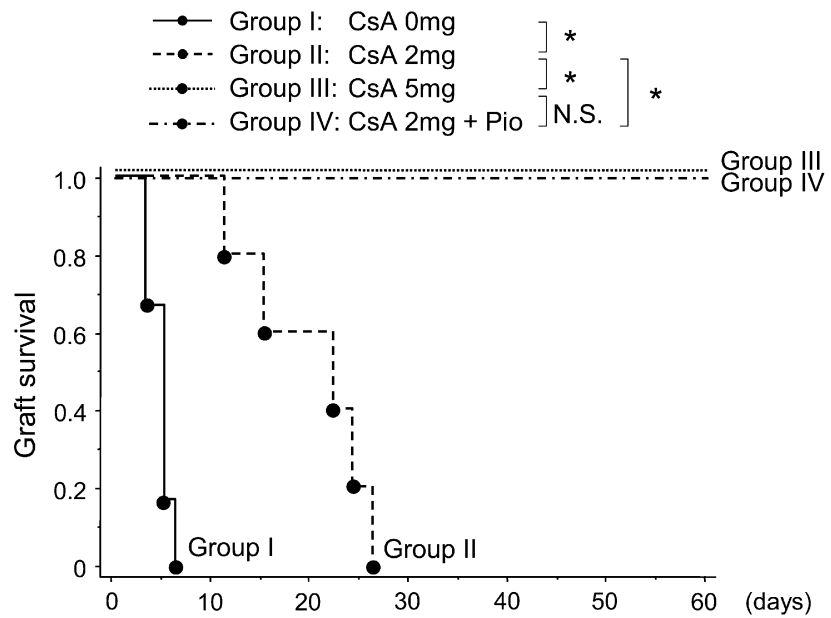

FIGURE 1. Effects of pioglitazone and cyclosporine on allograft survival in our rat heart transplantation model. $* P<.005$. Pio, Pioglitazone; CsA, cyclosporine A; NS, not significant. Data were analyzed by using a logrank test of Kaplan-Meier analysis. were no significant differences between groups III and IV (Figure 2).

\section{Reduction of Serum IFN- $\gamma$ and IL-2 Levels}

Because suppression of IL- 2 and IFN- $\gamma$ levels offers a biologic response to CsA, ${ }^{20,21}$ we measured serum levels of IL-2 and IFN- $\gamma$ at 1 week after transplantation. At 1 week after transplantation, CsA treatment significantly decreased those levels in a dose-dependent manner. Compared with group II, pioglitazone treatment with low-dose CsA (group IV) significantly decreased serum IL- 2 and IFN- $\gamma$ levels, and there were no significant differences in those in group III (Figure 3).

\section{Protection of Renal Function}

Because plasma BUN and creatinine levels are ordinary markers of functional nephrotoxic damage to the kidney, we measured these levels and evaluated creatinine clearance. At 1 week after transplantation, CsA treatment significantly increased plasma levels of BUN and creatinine and decreased creatinine clearance in a dose-dependent manner. This CsA-induced renal dysfunction was suppressed by pioglitazone treatment with low-dose CsA (Figure 4).

\section{Suppression of Renal Apoptosis}

At 1 week after transplantation, TUNEL-stained sections showed that CsA significantly increased the number of TUNEL-positive cells in a dose-dependent manner. By means of pioglitazone treatment with low-dose CsA, far less apoptotic renal cells were present in group IV compared with numbers seen in groups II and III (Figure 5). To further confirm the renal apoptosis, we performed immunofluorescent staining of Bax, which is one of the key components for cell-induced apoptosis. Although CsA treatment increased renal Bax expression in a dose-dependent manner, the CsA-induced Bax upregulation was apparently suppressed by pioglitazone treatment with low-dose CsA.

\section{Regulation of Renal PPAR- $\gamma$ and TGF- $\beta 1$ Expression}

Immunofluorescent staining has shown that pioglitazone treatment upregulates PPAR- $\gamma$ expression in the recipient kidneys at 1 week after transplantation (Figure 6, A). Because TGF- $\beta 1$ plays a pivotal role in the development of CsA nephropathy, ${ }^{22}$ we next evaluated TGF- $\beta 1$ protein expression in the recipient kidneys by means of enzyme-linked immunosorbent assay, as well as by means of immunofluorescent staining. Although CsA treatment significantly increased renal TGF- $\beta 1$ expression in a dose-dependent manner, the CsA-induced TGF- $\beta 1$ stimulation was significantly suppressed by pioglitazone treatment with low-dose CsA (Figure 6).

\section{DISCUSSION}

To the best our knowledge, the present study provides the first evidence that the PPAR- $\gamma$ agonist pioglitazone can 

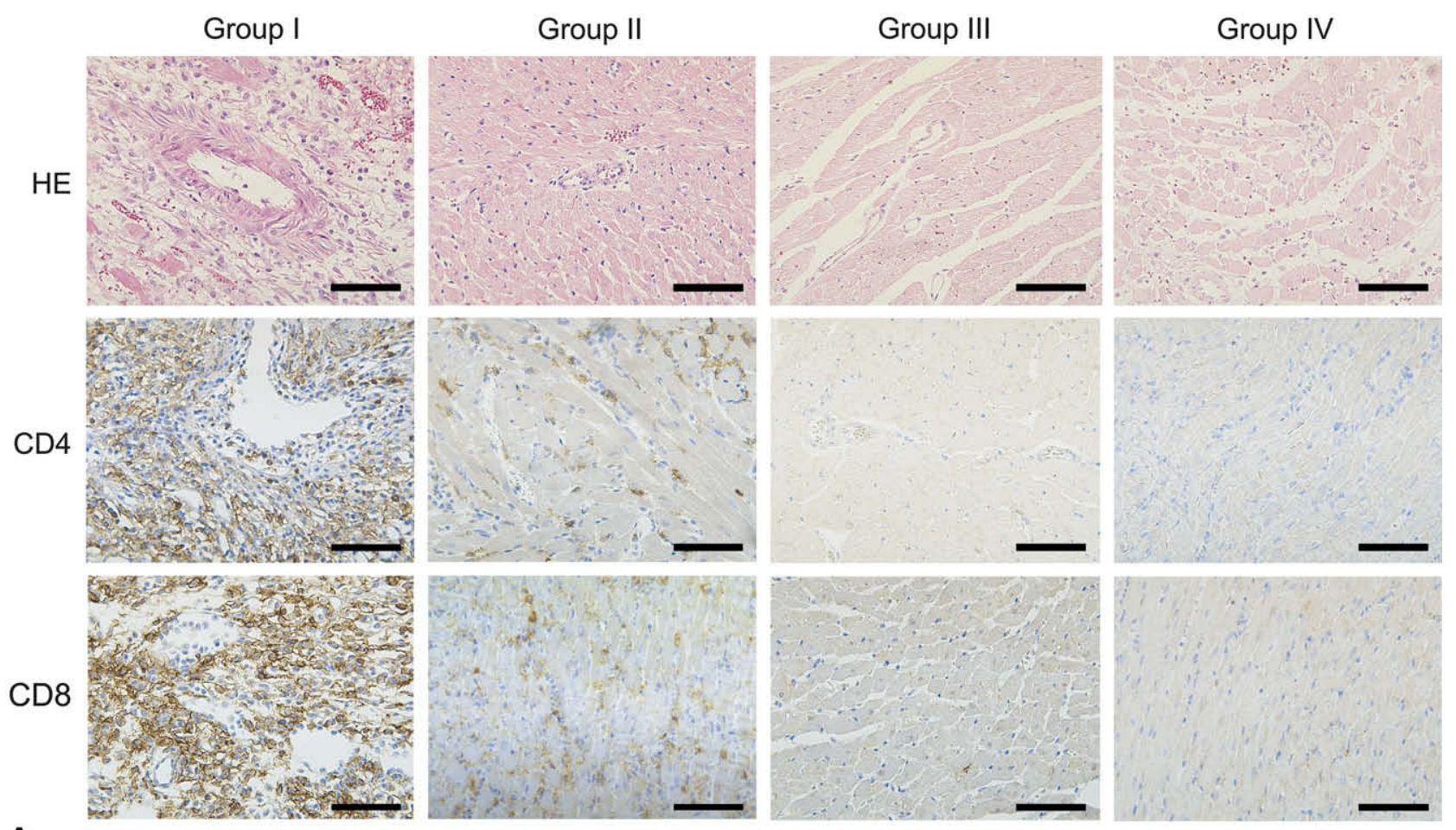

A
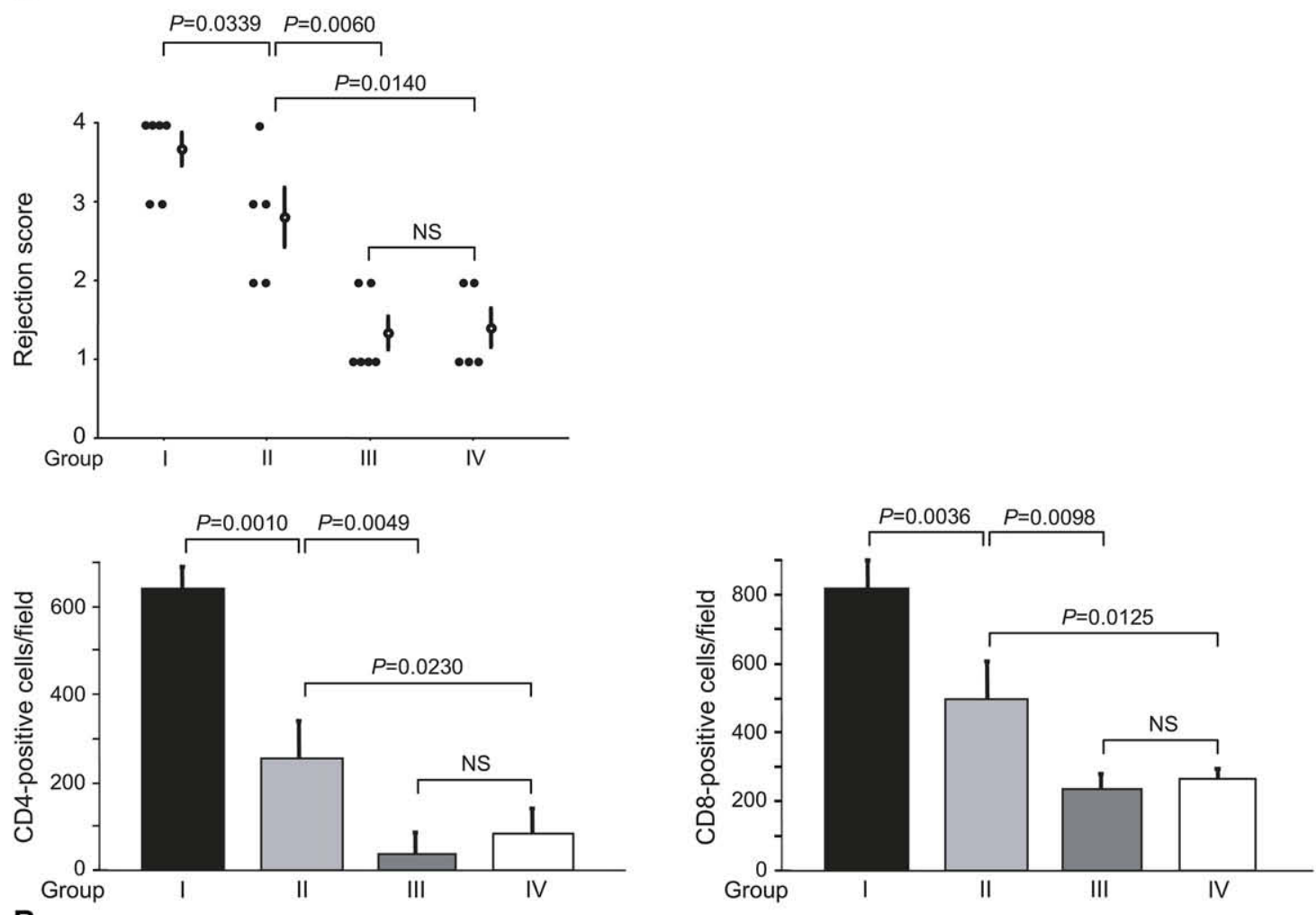

B

FIGURE 2. Histologic findings of cardiac allografts in acute rejection. A, Hematoxylin and eosin $(H E)$ staining and immunohistochemical staining of CD4 and CD8. Bar $=100 \mu \mathrm{m}$. B, Rejection score. C, Quantitative analysis of CD4 ${ }^{+}$and CD8 ${ }^{+}$cells. NS, Not significant. All data are expressed as means \pm standard errors of the mean. 


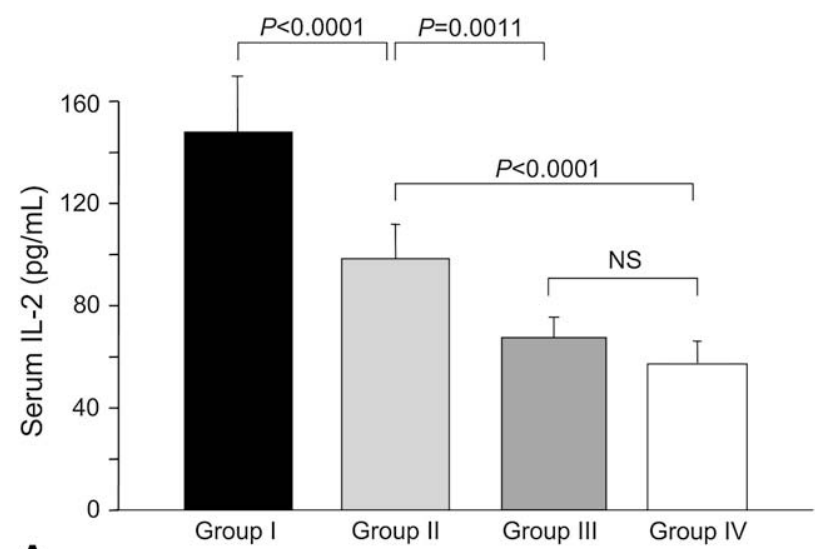

A

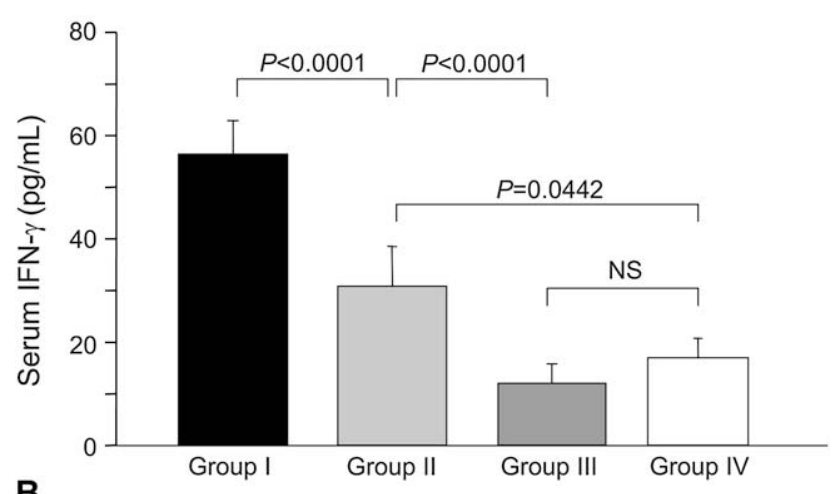

FIGURE 3. Serum concentrations of interleukin $2(I L-2 ; \mathrm{A})$ and interferon $\gamma(I F N-\gamma ;$ B) by means of enzyme-linked immunosorbent assay. NS, Not significant. All data are expressed as means \pm standard errors of the mean.

reduce the dose of CsA for renoprotection with sufficient immunosuppressive effects in rat heart transplantation. In a nonsurgical setting Pereira and colleagues ${ }^{16}$ have recently reported that pioglitazone limits CsA nephrotoxicity, possibly because of a downregulation of plasminogen activator inhibitor 1 and an overexpression of the regulatory factor Smad7 in rats. The study evaluated rat renal function, such as serum creatinine values, and CsA nephrotoxicity, such as arteriopathy, in the 28-day treatment. Although our study could not evaluate such a chronic CsA nephrotoxicity because of the survival of CsA-treated cardiac allografts, we have evaluated recipient renal function and apoptosis in detail at 1 week after heart transplantation. The major findings of the present study are that pioglitazone treatment in association with low-dose CsA leads to (1) prolongation of cardiac allograft survival similar to that seen with conventional high-dose CsA treatment and (2) significant attenuation of CsA-induced nephrotoxicity (possibly through upregulation of PPAR- $\gamma$ and downregulation of TGF- $\beta 1$ ) in a rat heart transplantation model. Because renal failure caused by CsA treatment is one of the serious problems occurring after transplantation of nonrenal organs, ${ }^{4}$ the dose reduction of CsA caused by the combination of pioglitazone could bring beneficial effects in patients with heart transplantations.

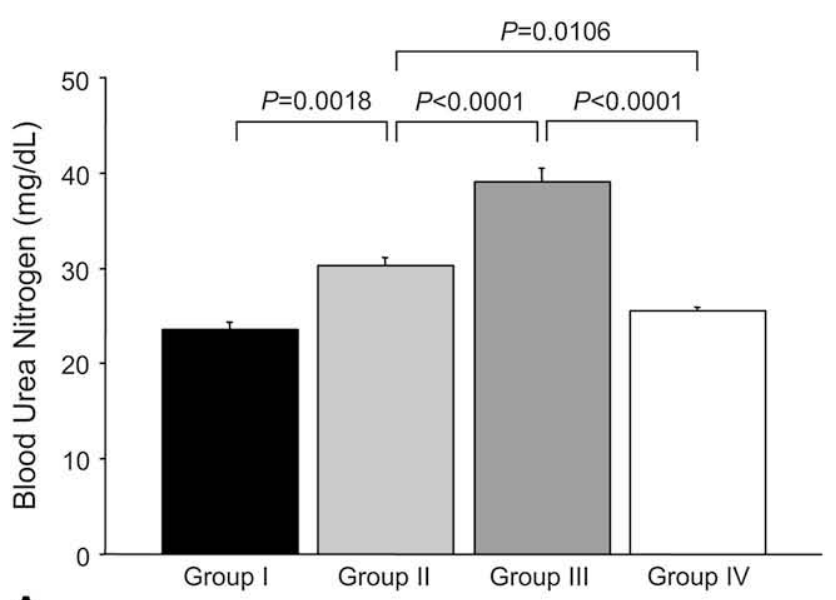

A

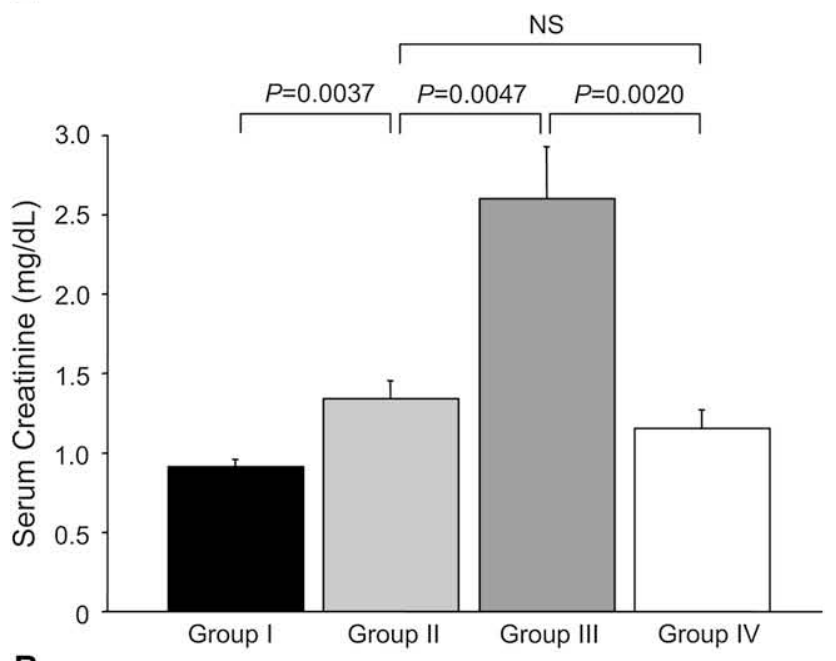

B

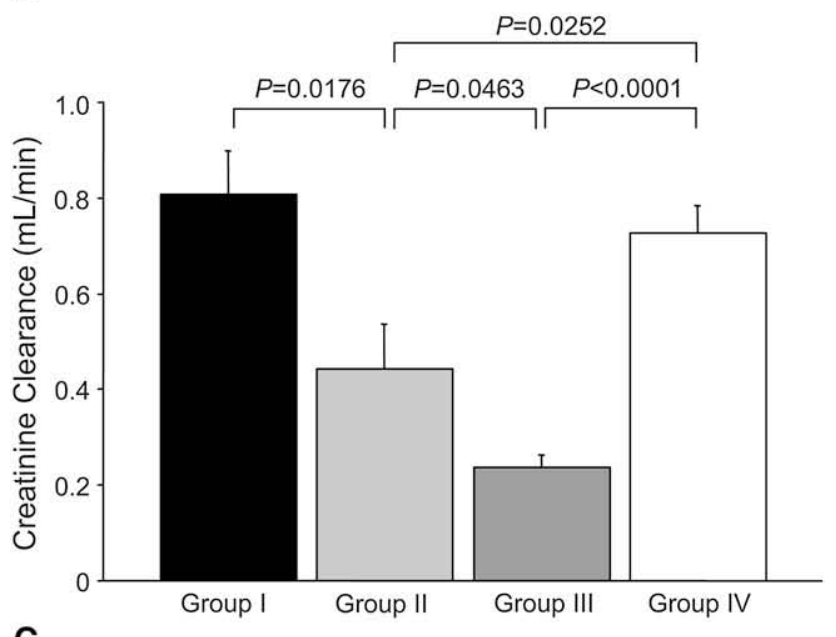

FIGURE 4. Effects of pioglitazone and cyclosporine on recipient renal function: A, serum BUN levels; B, serum creatinine levels; and C, creatinine clearance. $N S$, Not significant. All data are expressed as means \pm standard errors of the mean. 


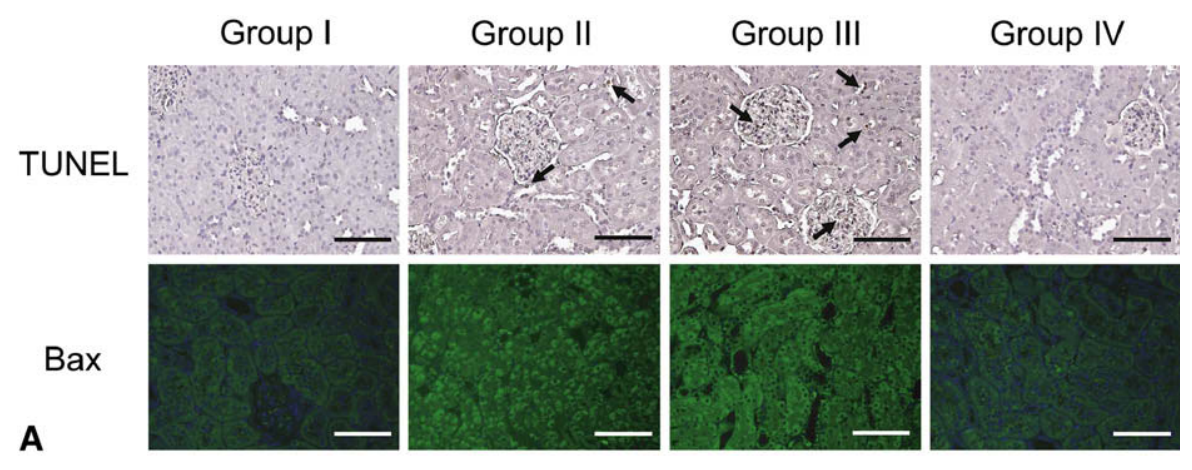

B

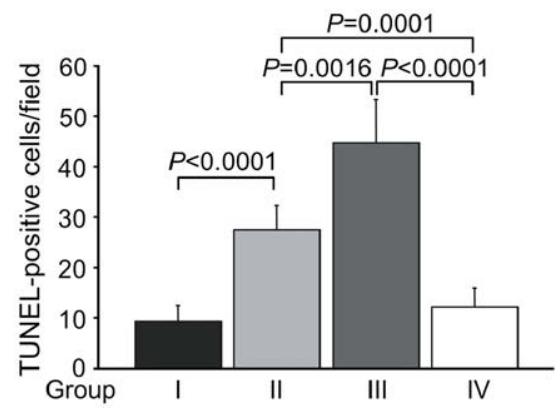

FIGURE 5. Histologic findings of renal apoptosis after heart transplantation. A, transferase-mediated dUTP-biotin nick end labeling (TUNEL) staining and immunofluorescent staining of Bax. TUNEL-positive cells (brown) are shown by arrows. Intracellular expression of Bax is identified by the green emission. Cell nuclei are identified by the blue emission. Bar $=100 \mu \mathrm{m}$. B, Quantitative analysis of TUNEL-positive cells. All data are expressed as means \pm standard errors of the mean.
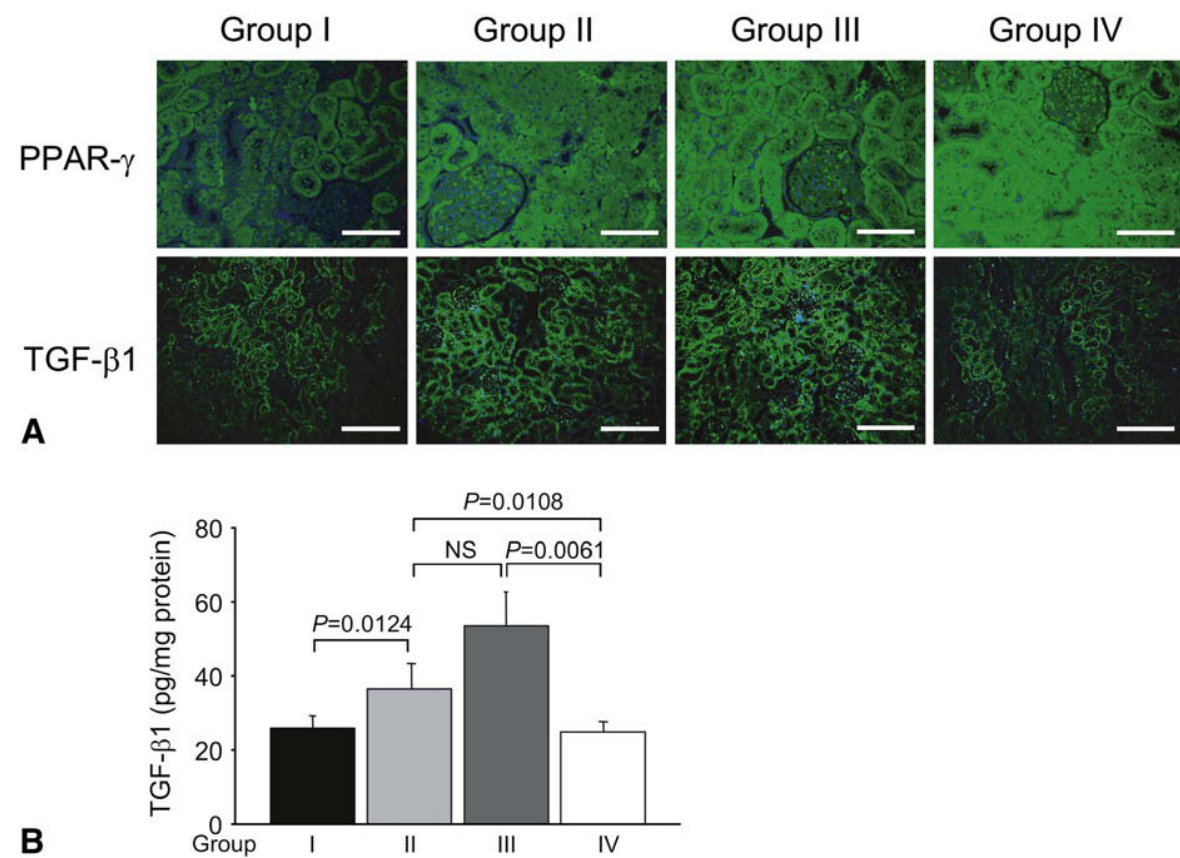

FIGURE 6. Renal expression of peroxisome proliferator-activated receptor $\gamma(P P A R-\gamma)$ and transforming growth factor $\beta 1$ (TGF- $\beta 1)$ after heart transplantation. A, Immunofluorescent staining of PPAR- $\gamma$ and TGF- $\beta$ 1. Intracellular expression of PPAR- $\gamma$ and TGF- $\beta 1$ is identified by the green emission. Cell nuclei are identified by the blue emission. Bar $=100 \mu \mathrm{m}$. B, TGF- $\beta 1$ protein levels in recipient kidney, as determined by means of enzyme-linked immunosorbent assay. NS, Not significant. All data are expressed as means \pm standard errors of the mean. 
It is not surprising that pioglitazone enhanced PPAR- $\gamma$ expression in the recipient kidneys. Previous in vitro experiments have also shown that pioglitazone treatment increases mRNA expression and activity of PPAR- $\gamma$ in renal cells. ${ }^{23}$ Recently, several experimental studies demonstrated that PPAR- $\gamma$ activation with thiazolidinediones has protective effects against both heart ${ }^{24-26}$ and kidney ${ }^{27,28}$ disorders, including anti-inflammatory and antiproliferative properties. Therefore there are obvious potential benefits of graft protection and renoprotection induced by PPAR- $\gamma$ activation with pioglitazone.

The present study showed that CsA administration resulted in dose-dependent nephrotoxicity, as evidenced by a significant increase in plasma BUN and creatinine levels, and a significant reduction in creatinine clearance at 1 week after transplantation. These renal functional disturbances were further confirmed by means of histopathologic findings, such as apoptosis in glomerular and tubular epithelial cells. In recent years, renal cell apoptosis has been proposed as a putative primary pathomechanism that might underlie progression of chronic renal disease, including nephrosclerosis. ${ }^{29,30}$ In the present study pioglitazone treatment combined with low-dose CsA significantly ameliorated both functional and histopathologic damage in recipient kidneys. Based on these findings, we suggest that pioglitazone can provide good renoprotection against CsAinduced nephrotoxicity.

TGF- $\beta$ is a multifunctional cytokine that plays an important role as one of the major pathogenic factors in fibrotic changes in kidney diseases. ${ }^{31}$ It was reported that CsA administration induces histologic and functional alterations of the kidney parallel with an increase in TGF- $\beta 1$ levels. ${ }^{22,32}$ In the present study renal TGF- $\beta 1$ levels were upregulated by CsA treatment in a dose-dependent manner. However, pioglitazone treatment with low-dose CsA significantly suppressed the upregulation of TGF- $\beta 1$ compared with highdose CsA treatment or low-dose CsA alone. Recently, PPAR- $\gamma$ activation was reported to inhibit TGF- $\beta$ expression, resulting in the suppression of neointima formation. ${ }^{33,34}$ In addition, TGF- $\beta$ can closely induce apoptotic signaling in renal cells. ${ }^{29}$ The suppression of TGF- $\beta 1$ signaling might be a key mechanism for pioglitazone-induced renoprotection against CsA nephrotoxicity.

As expected, the current study demonstrates that the calcineurin inhibitor CsA decreased serum levels of IL-2 and IFN- $\gamma$ in a dose-dependent manner. Because both IL-2 and IFN- $\gamma$ are rejection products in activated lymphocytes, they are both good markers of the pharmacodynamic immunosuppressive effects of CsA. ${ }^{20,21}$ Moreover, thiazolidinedione was recently reported to mediate inhibition of IL-2 or IFN- $\gamma$ secretion. ${ }^{15,35}$ Successful posttransplantation immunosuppression must balance the suppression of graft rejection with a minimal CsA nephrotoxicity. At this point, pioglitazone with low-dose CsA is a suitable regimen for immunosuppressive treatment during heart transplantation because we have shown that pioglitazone with low-dose CsA provided (1) less graft rejection than high-dose CsA and (2) less renal damage than high-dose CsA. Interestingly, the protective effects of pioglitazone with low-dose CsA were greater than those of low-dose CsA alone. We believe that the synergistic effects of pioglitazone and low-dose CsA lead to both graft protection and renoprotection against CsA-induced nephrotoxicity.

Although pioglitazone has some clinical drawbacks, such as causing fluid retention, congestive heart failure, fractures, and hepatocellular injury, we firmly believe that pioglitazone has numerous advantages as long as the dose is optimal. In accordance with the previous report, ${ }^{36}$ we administered the same dose $\left(3 \mathrm{mg} \cdot \mathrm{kg}^{-1} \cdot \mathrm{d}^{-1}\right)$ of pioglitazone in this study without those adverse effects. In clinical settings various immunosuppressive regimens based on the association of low-dose CsA with other drugs are adopted during posttransplantation management. For example, steroids are also important immunosuppressive agents in addition to CsA in organ transplantation. However, they have the potential to increase the incidence of infection, and steroid withdrawal can result in an increase of posttransplantation coronary artery disease. ${ }^{37}$ Pioglitazone might be a major alternative to steroids because of its pharmacologic kinetics.

This study presents some limitations that deserve acknowledgement. The first limitation is that experiments were performed with a rat heterotopic nonworking heart transplantation model. Although this model has been widely accepted as a standard experimental model of heart transplantation, there are some discrepancies between the model and clinical heart transplantation with regard to species, nonworking heart, and heterotopic transplantation. Therefore the beneficial effects of pioglitazone on immune response and renal function in the present study might be an extrapolation from a nonclinically relevant rat model to clinical human heart transplantation. Further studies are needed to determine the accurate effects of pioglitazone on both cardiac allografts and recipient kidneys during heart transplantation.

The second limitation is that the present study has not established the dose-response or time-response relation between pioglitazone and CsA with regard to either the reduction of cardiac rejection or the renal toxicity of CsA. Because these relations might be very narrow, the lack of these relations could invalidate the clinical relevance in the present study.

The final limitation is represented by the lack of mRNA analysis, such as real-time polymerase chain reaction, to evaluate renal expression of signal pathways in pioglitazone treatment.

In conclusion, pioglitazone treatment with low-dose CsA leads to synergistic protective effects for cardiac allografts and recipient kidneys. Pioglitazone has a potential use for immunosuppressive regimens based on the combination with low-dose CsA, providing minimal CsA-induced nephrotoxicity. 


\section{References}

1. Lechler RI, Sykes M, Thomson AW, Turka LA. Organ transplantation-how much of the promise has been realized? Nat Med. 2005;11:605-13.

2. Mulligan MS, Shearon TH, Weill D, Pagani FD, Moore J, Murray S. Heart and lung transplantation in the United States, 1997-2006. Am J Transplant. 2008; 8(suppl):977-87.

3. Flechner SM, Kobashigawa J, Klintmalm G. Calcineurin inhibitor-sparing regimens in solid organ transplantation: focus on improving renal function and nephrotoxicity. Clin Transplant. 2008;22:1-15

4. Ojo AO, Held PJ, Port FK, Wolfe RA, Leichtman AB, Young EW, et al. Chronic renal failure after transplantation of a nonrenal organ. $N$ Engl J Med. 2003;349: 931-40.

5. Mourad M, Wallemacq P, De Meyer M, Malaise J, De Pauw L, Eddour DC, et al. Biotransformation enzymes and drug transporters pharmacogenetics in relation to immunosuppressive drugs: impact on pharmacokinetics and clinical outcome. Transplantation. 2008;85(suppl):S19-24.

6. Grinyo JM, Cruzado JM, Millan O, Caldes A, Sabate I, Gil-Vernet S, et al. Low-dose cyclosporine with mycophenolate mofetil induces similar calcineurin activity and cytokine inhibition as does standard-dose cyclosporine in stable renal allografts. Transplantation. 2004;78:1400-3.

7. Groetzner J, Kaczmarek I, Meiser B, Muller M, Daebritz S, Reichart B. Sirolimus and mycophenolate mofetil as calcineurin inhibitor-free immunosuppression in a cardiac transplant patient with chronic renal failure. J Heart Lung Transplant. 2004;23:770-3.

8. Schweiger M, Wasler A, Prenner G, Stiegler P, Stadlbauer V, Schwarz M, et al. Everolimus and reduced cyclosporine trough levels in maintenance heart transplant recipients. Transpl Immunol. 2006;16:46-51.

9. Abdelrahman M, Sivarajah A, Thiemermann C. Beneficial effects of PPARgamma ligands in ischemia-reperfusion injury, inflammation and shock. Cardiovasc Res. 2005;65:772-81.

10. Kasai T, Miyauchi K, Yokoyama T, Kajimoto K, Sumiyoshi K, Kubota N, et al. Pioglitazone attenuates neointimal thickening via suppression of the early inflammatory response in a porcine coronary after stenting. Atherosclerosis. 2008;197:612-9.

11. Yuan Z, Liu Y, Liu Y, Zhang J, Kishimoto C, Wang Y, et al. Cardioprotective effects of peroxisome proliferator activated receptor gamma activators on acute myocarditis: anti-inflammatory actions associated with nuclear factor kappaB blockade. Heart. 2005;91:1203-8.

12. Agarwal R, Saha C, Battiwala M, Vasavada N, Curley T, Chase SD, et al. A pilot randomized controlled trial of renal protection with pioglitazone in diabetic nephropathy. Kidney Int. 2005;68:285-92.

13. Ohga S, Shikata K, Yozai K, Okada S, Ogawa D, Usui H, et al. Thiazolidinedione ameliorates renal injury in experimental diabetic rats through anti-inflammatory effects mediated by inhibition of NF-kappaB activation. Am J Physiol Renal Physiol. 2007;292:F1141-50.

14. Sarafidis PA, Bakris GL. Protection of the kidney by thiazolidinediones: an assessment from bench to bedside. Kidney Int. 2006;70:1223-33.

15. Kosuge H, Haraguchi G, Koga N, Maejima Y, Suzuki J, Isobe M. Pioglitazone prevents acute and chronic cardiac allograft rejection. Circulation. 2006;113: 2613-22.

16. Pereira MG, Camara NO, Campaholle G, Cenedeze MA, de Paula AT, V, dos Reis MA, et al. Pioglitazone limits cyclosporine nephrotoxicity in rats. Int Immunopharmacol. 2006;6:1943-51.

17. Ono K, Lindsey ES. Improved technique of heart transplantation in rats. J Thorac Cardiovasc Surg. 1969;57:225-9.

18. Billingham ME, Cary NR, Hammond ME, Kemnitz J, Marboe C, McCallister HA, et al. A working formulation for the standardization of nomenclature in the diagnosis of heart and lung rejection: Heart Rejection Study Group. The International Society for Heart Transplantation. J Heart Transplant. 1990;9:587-93.
19. Stewart S, Winters GL, Fishbein MC, Tazelaar HD, Kobashigawa J, Abrams J et al. Revision of the 1990 working formulation for the standardization of nomenclature in the diagnosis of heart rejection. J Heart Lung Transplant. 2005;24: 1710-20.

20. Batiuk TD, Kung L, Halloran PF. Evidence that calcineurin is rate-limiting for primary human lymphocyte activation. J Clin Invest. 1997;100:1894-901.

21. Salom RN, Maguire JA, Hancock WW. Mechanism of a clinically relevant protocol to induce tolerance of cardiac allografts. Perioperative donor spleen cells plus cyclosporine suppress IL-2 and interferon-gamma production. Transplanta tion. 1993;56:1309-14.

22. Shihab FS, Andoh TF, Tanner AM, Noble NA, Border WA, Franceschini N, et al Role of transforming growth factor-beta 1 in experimental chronic cyclosporine nephropathy. Kidney Int. 1996;49:1141-51.

23. Kanjanabuch T, Ma LJ, Chen J, Pozzi A, Guan Y, Mundel P, et al. PPAR-gamma agonist protects podocytes from injury. Kidney Int. 2007;71:1232-9.

24. Cao Z, Ye P, Long C, Chen K, Li X, Wang H. Effect of pioglitazone, a peroxisome proliferator-activated receptor gamma agonist, on ischemia-reperfusion injury in rats. Pharmacology. 2007;79:184-92.

25. Wayman NS, Hattori Y, McDonald MC, Mota-Filipe H, Cuzzocrea S, Pisano B, et al. Ligands of the peroxisome proliferator-activated receptors (PPAR-gamma and PPAR-alpha) reduce myocardial infarct size. FASEB J. 2002;16:1027-40.

26. Yue TL, Chen J, Bao W, Narayanan PK, Bril A, Jiang W, et al. In vivo myocardial protection from ischemia/reperfusion injury by the peroxisome proliferator-activated receptor-gamma agonist rosiglitazone. Circulation. 2001;104:2588-94.

27. Newaz M, Yousefipour Z, Oyekan A. Role of PPAR-gamma on the pathogenesis and vascular changes in glycerol-induced acute renal failure. Pharmacol Res. 2006;54:234-40.

28. Sommer M, Wolf G. Rosiglitazone increases PPARgamma in renal tubular epithelial cells and protects against damage by hydrogen peroxide. Am J Nephrol. 2007 27:425-34.

29. Bottinger EP, Bitzer M. TGF-beta signaling in renal disease. J Am Soc Nephrol. 2002;13:2600-10.

30. Schiffer M, Bitzer M, Roberts IS, Kopp JB, ten Dijke P, Mundel P, et al. Apoptosis in podocytes induced by TGF-beta and Smad7. J Clin Invest. 2001;108: 807-16.

31. Border WA, Noble NA. Transforming growth factor beta in tissue fibrosis. N Engl J Med. 1994;331:1286-92.

32. Khanna A, Kapur S, Sharma V, Li B, Suthanthiran M. In vivo hyperexpression of transforming growth factor-betal in mice: stimulation by cyclosporine. Transplantation. 1997;63:1037-9.

33. Fu M, Zhang J, Zhu X, Myles DE, Willson TM, Liu X, et al. Peroxisome proliferator-activated receptor gamma inhibits transforming growth factor beta-induced connective tissue growth factor expression in human aortic smooth muscle cells by interfering with Smad3. J Biol Chem. 2001;276:45888-94.

34. Joner M, Farb A, Cheng Q, Finn AV, Acampado E, Burke AP, et al. Pioglitazone inhibits in-stent restenosis in atherosclerotic rabbits by targeting transforming growth factor-beta and MCP-1. Arterioscler Thromb Vasc Biol. 2007;27:182-9.

35. Clark RB, Bishop-Bailey D, Estrada-Hernandez T, Hla T, Puddington L, Padula SJ. The nuclear receptor PPAR gamma and immunoregulation: PPAR gamma mediates inhibition of helper T cell responses. J Immunol. 2000;164: 1364-71.

36. Shiomi T, Tsutsui H, Hayashidani S, Suematsu N, Ikeuchi M, Wen J, et al. Pioglitazone, a peroxisome proliferator-activated receptor-gamma agonist, attenuates left ventricular remodeling and failure after experimental myocardial infarction. Circulation. 2002;106:3126-32.

37. Rosenbaum DH, Adams BC, Mitchell JD, Jessen ME, Paul MC, Kaiser PA, et al Effects of early steroid withdrawal after heart transplantation. Ann Thorac Surg. 2006;82:637-44 